\title{
Y llegó el día de la venganza: el maquis, la guerra continúa
}

\author{
FRANCESC SÁNCHEZ LOBERA \\ Universitat de Barcelona
}

\section{Resumen}

La leyenda del maquis forma parte de nuestro imaginario colectivo pero el gran público desconoce casi todo de esta realidad de la postguerra española. A través de la película Y llegó el día de la venganza de Fred Zinnemann pretendo introducir esta realidad social aportando una serie de hechos y una bibliografía que permitan al investigador o al curioso saber algo más de la misma película y de la cuestión.

Palabras clave: Franquismo, maquis, guerrilla antifranquista, guardia civil, guerra civil, segunda guerra mundial, dictadura, postguerra, guerra fría, censura, anarquismo, comunismo, frontera.

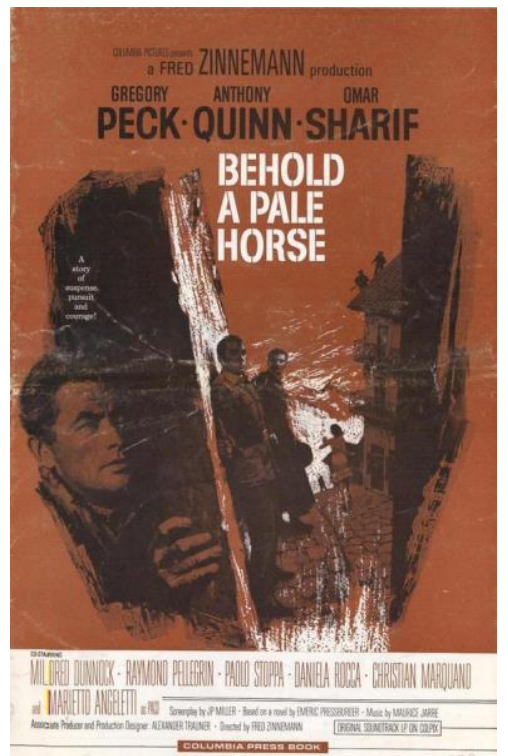

El fenómeno de la guerrilla durante la Guerra Civil española fue abordado por Hemingway en su novela For Whom the Bell Tolls (¿Por quién doblan las campanas?) que posteriormente fue llevada al cine por Sam Wood en 1943 en el contexto de la Segunda Guerra Mundial. Para que aparezca de nuevo este tema tenemos que esperar a 1964 el momento en el que llega Behold Pale a Horse (Y llegó el día de la venganza) de Fred Zinnemann. Y en el cine norteamericano, ninguna más. He elegido esta segunda película sobre esta temática porque el fenómeno de la guerrilla antifranquista, comúnmente conocido como el maquis ${ }^{1}$, propiamente se configura y toma fuerza cuando la Guerra Civil ha concluido, periodo de postguerra en el que se inicia la historia del film.

Manuel Artigues (Gregory Peck), al terminar la Guerra Civil se encuentra con sus compañeros en el paso fronterizo, pero quiere regresar a España. Para él la guerra no ha terminado. Veinte años después un niño llamado Paco (Marietto Angeletti) acude a Pau en su búsqueda para que vengué la muerte de su padre, compañero de Artigues. En Sant Martin el Capitán Viñolas (Anthony Quinn) ante la inminente muerte de la madre de Artigues quiere preparar una trampa a su viejo rival. El padre Francisco (Omar Sharif) va a ver a la

\footnotetext{
${ }^{1}$ El término maquis es francés y proviene del corso y del italiano macchia, que equivale a paisaje de arbustos o matorrales. Sinónimo de resistente, una traducción libre de maquis podría ser la de echarse al monte.
} 
anciana y recibe una petición: avisar a Manel Artigues de la encerrona de Viñolas. Francisco pues se encuentra en un dilema: colaborar con las fuerzas del orden callándose o cumplir el último deseo de una madre para salvar la vida de su hijo.

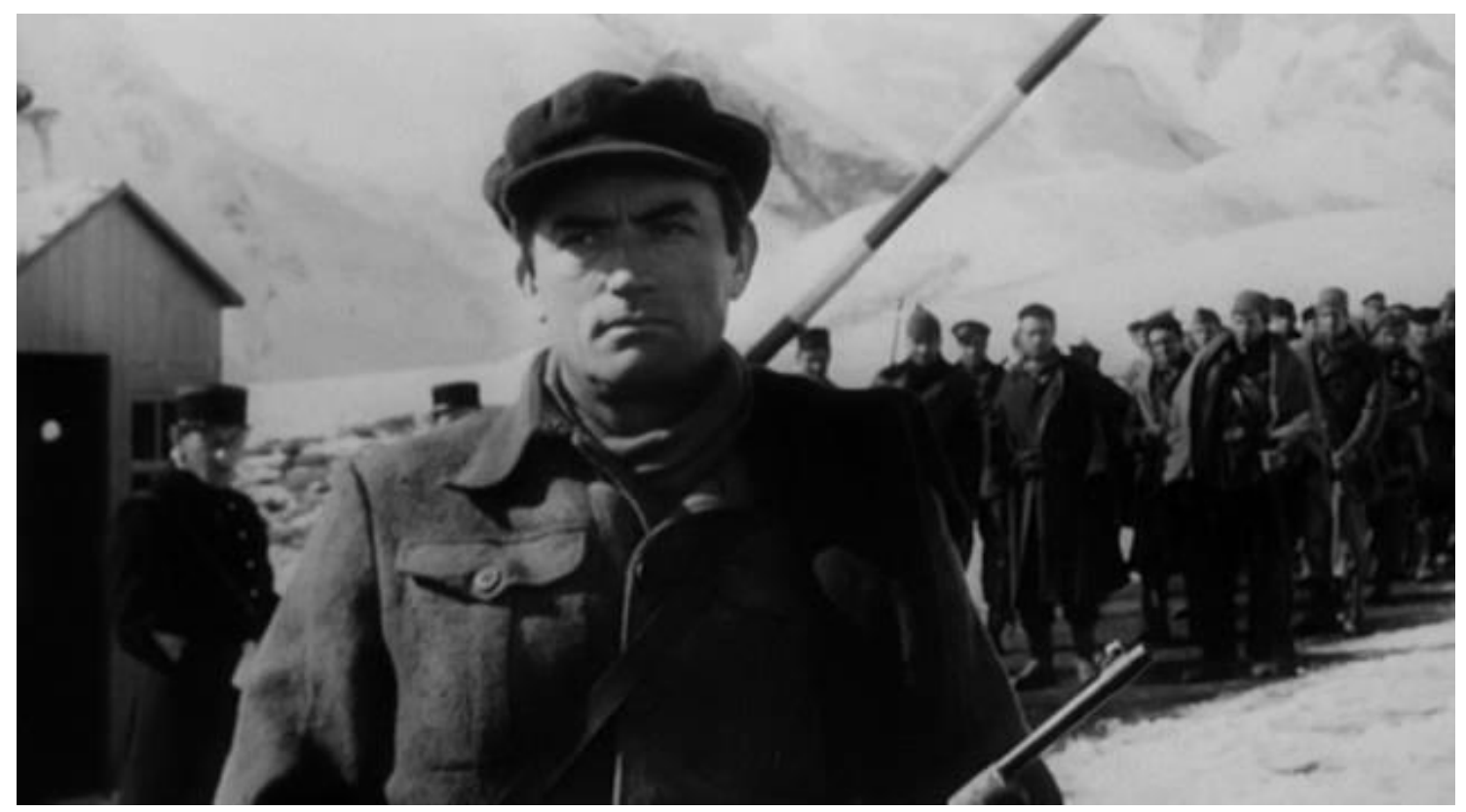

Fred Zinnemann antes de esta película había rodado en 1952 el western High Noon (Solo ante el peligro), y un año después, en 1953, From Here to Eternity (De aquí a la eternidad), que nos cuenta la transformación de la vida de unos militares durante el ataque japonés sobre Pearl Harbor. Posteriormente, en 1966, nos presentó A Man for All Seasons (Un hombre para la eternidad), que nos cuenta el momento clave de la vida de Tomás Moro en el contexto de la Reforma anglicana. Y llegó el día de la venganza, basada en la novela Killing a Mouse in Sunday de Emeric Pressburger, no sólo fue prohibida por el régimen en España, sino que incluso esta misma dictadura, como nos cuentan Pedro Nogales Cárdenas, Antonio Pérez-Portabella López, y José Carlos Suárez Fernández, primero quiso que se abandonara la producción de la película y luego exigió censurar el guion:

En 1963 los altos funcionarios del gobierno español reciben informes realizados tras la lectura de la novela que aún aumentan más sus objeciones al film y piden a la Columbia que abandone el proyecto o que sitúe la trama en un país imaginario. Las sanciones se agravan, e incluso se llega a pedir a la Columbia que el guion pase previamente por la censura española, algo realmente sorprendente teniendo en cuenta que se trata de una producción estadounidense fuera del territorio español. Finalmente, el film se estrena en Estados Unidos, pasando más bien desapercibido, y el gobierno español sigue muy enfadado con la Columbia e intenta evitar su distribución en el mundo, especialmente en América Latina, e incluso intenta prohibir su pase en la televisión americana.

¿Pero cuáles son las razones de este enfado? Para las autoridades españolas este es un film claramente antiespañol por la mala imagen que da de la Guardia Civil. En concreto les molesta la imagen del teniente Viñolas con el caballo y especialmente con la amiga y en la casa de la prostituta antes de matar al guerrillero. El final tampoco será del agrado de las autoridades, ya que, 
aunque se mate al guerrillero, el hecho de que suenen las campanas de la iglesia no le parece adecuado. ${ }^{2}$

Fue tal la irritación por esta película que el régimen, encabezado por Manuel Fraga Iribarne como Ministro de Información y Turismo, sancionó a la Columbia Pictures dejándola durante años fuera del mercado de distribución en España, llegando incluso a la desaparición de la filial española, que tuvo que vender sus stocks y su negocio de distribución a la empresa Mundial Films, hasta que llegó a un acuerdo con el estudio por el que intercambiaban las sanciones por «la distribución en Latinoamérica de seis películas españolas» ${ }^{3}$. No obstante, la presión continúo cuando la Columbia permitió que la película fuera emitida en los Estados Unidos por el canal de televisión CBS (Columbia Broadcasting System). Por lo que respecta a la cuenta de resultados de la película no fue buena, pasa desapercibida, y en España no se estrenó hasta el 14 de mayo de 1979, casi cuatro años después de la muerte de Franco.

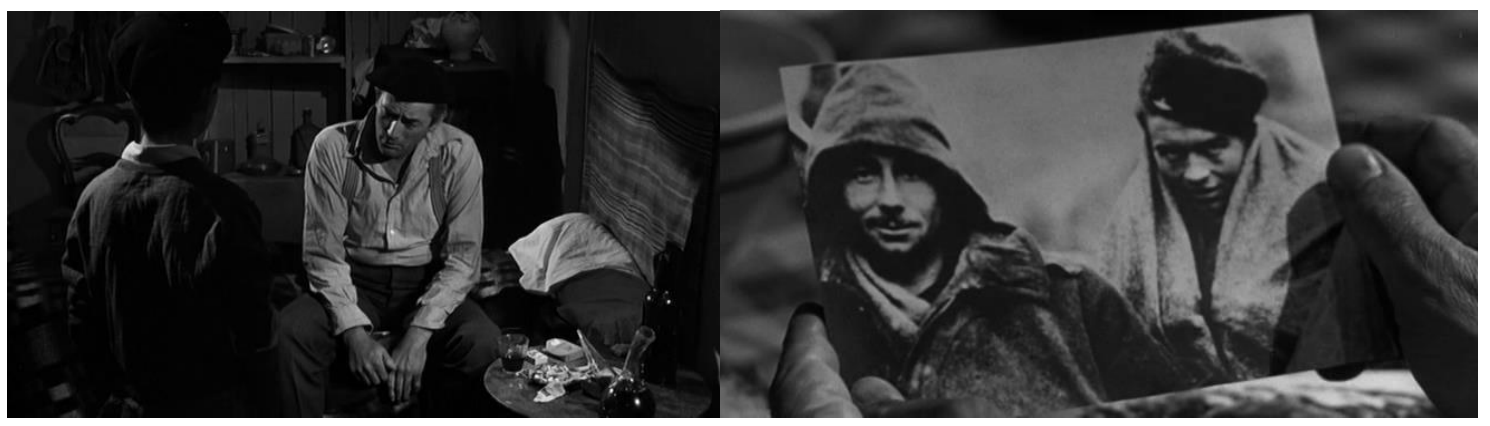

El maquis fue un fenómeno español que se inició durante la Guerra Civil en el momento que los rebeldes fueron conquistando el territorio, y los individuos más significados y los que no quisieron engrosar las filas de los sublevados, se tiran al monte, primero para sobrevivir y luego combatir informalmente en forma de guerrillas a los nacionales. Estos son los que fueron conocidos bajo el nombre de huidos. Cuando la República pierde la Guerra Civil más de medio millón de personas abandona el país por los Pirineos hacía Francia y por el puerto de Alicante hacía el Norte de África. Para los que se quedaron les tocó vivir en el mejor de los casos bajo la bota de una dictadura implacable que duraría casi cuarenta años. El régimen dictatorial:

se mantiene gracias al terror y la represión hacia los vencidos. Decenas de miles personas (las cifras más bajas nos hablan de 90.000 durante la guerra y 60.000 finalizada ésta) serán asesinadas: ministros, diputados, dirigentes de partidos políticos y sindicatos, maestros, funcionarios, intelectuales, y sobre todo obreros, campesinos y jornaleros no fueron perdonados. Habrá más de 300.000 desparecidos. Con la postguerra decenas de miles mueren por las enfermedades asociadas al hambre (entre 1940 y 1942 mueren 78.000 personas por la tuberculosis) ${ }^{4}$.

\footnotetext{
2 NOGALES CÁRDENAS, Pedro. PÉREZ-PORTABELLA LÓPEZ, Antonio. SUÁREZ FERNÁNDEZ, José Carlos (2015). Y llegó el día de la venganza. Franco contra Hollywood. V Congreso Internacional de Historia y Cine Histórico. (https://e-archivo.uc3m.es/bitstream/handle/10016/24915/Llego_Nogales_CIHC_2017.pdf) [consulta: 1 de junio de 2019]

${ }^{3}$ Ibídem.

$4 \quad$ SÁNCHEZ, Francesc (2011) La guerrilla antifranquista. El Inconformista Digital. (http://www.elinconformistadigital.com/2011/07/11/la-guerrilla-antifranquista-por-francesc-sanchez/) [consulta: $1 \mathrm{de}$ junio de 2019].
} 
En cuanto a los que se fueron de España, los exiliados, no es:

suficientemente conocido que este medio millón de refugiados españoles en Francia estuvo retenido en algún momento en decenas de campos de concentración como el de Gurs, el de Argelès-sur-Mer, Saint-Cyprien y Barcarès, Septfons, Rivesaltes, Vernet d'Ariège, Sisteron, y Les Milles, entre otros. Al iniciarse la Segunda Guerra Mundial se producen dos fenómenos: 1. de un lado muchos ex combatientes españoles se enrolan primero en batallones de extranjeros del ejército francés, más tarde en la resistencia, y luego en el Ejército Libre (la $9^{\circ}$ Compañía, encuadrada en la División Leclerc, conocida también como la Nueve, que tuvo un papel destacado en la liberación de Paris, estaba formada por españoles), 2. por otro lado sucedió también lo peor ya que los españoles retenidos en suelo francés que no tenían el estatus de prisioneros de guerra, considerados apátridas por la dictadura española, terminaron en los campos de concentración y extermino alemanes (alrededor de 7.000), en el caso de los hombres hacía Mauthausen, y en el caso de las mujeres hacía Ravensbrük ${ }^{5}$.

Pues bien, estos combatientes más afortunados que habían logrado sobrevivir, sumados a los que se habían escondido en muchas montañas del país, pondrán en marcha una guerra informal contra el régimen en forma de guerrillas.

El objetivo de los guerrilleros era infringir el máximo de daño en las fuerzas de un régimen fascista que seguía haciendo la guerra contra los perdedores matando a media España, y provocar tanto un levantamiento popular como una intervención militar por parte de las democracias occidentales, en un momento en que los aliados estaban derrotando a la Alemania de Hitler y a la Italia de Mussolini.

En este contexto debe entenderse la operación Reconquista de España sobre la Vall d'Aran efectuada en el mes de octubre de 1944:

más de 3.000 guerrilleros, encuadrados en 12 brigadas bajo el mando militar del antiguo coronel Vicente López Tovar, se enfrentaron a 40.000 soldados y guardias civiles. La operación es un fracaso: por parte del maquis hay 129 muertos, 241 heridos y 218 prisioneros. El ejército de Franco tras estos hechos refuerza su despliegue en los Pirineos hasta alcanzar los 100.000 efectivos. Los aliados, que pronto ganarían la Segunda Guerra Mundial, nunca entraran en España ${ }^{6}$.

La operación sea porque estaba mal diseñada, ejecutada, porque finalmente la abortase Santiago Carrillo, o porque el número de fuerzas enfrentadas no era equiparable, será un auténtico fracaso. No hubo ni intervención aliada ni levantamiento popular alguno.

Sin embargo, el Partido Comunista de España organiza otras guerrillas importantes como son las de Granada-Málaga y la de Levante. La Agrupación Guerrillera de Levante se extiende por las zonas limítrofes de Teruel, Valencia y Cuenca. Progresivamente se van constituyendo las Agrupaciones Guerrilleras del Centro, de Extremadura, de Andalucía, de Galicia y León y de Asturias-Santander,

\footnotetext{
${ }^{5}$ SÁNCHEZ, $\quad$ Francesc (2016) $\quad \underline{\text { Refugiados. }} . \quad$ El Inconformista $\quad$ Digital. (http://www.elinconformistadigital.com/2016/01/27/refugiados-por-francesc-sanchez/) [consulta: 1 de junio de 2019] 6 SÁNCHEZ, Francesc (2011) La guerrilla antifranquista. El Inconformista Digital. (http://www.elinconformistadigital.com/2011/07/11/la-guerrilla-antifranquista-por-francesc-sanchez/) [consulta: 1 de junio de 2019].
} 
siempre bajo el control del PCE. Un cálculo estimado nos dice que hubo entre 25.000 y 30.000 represaliados por la resistencia guerrillera ${ }^{7}$.

El maquis estuvo en activo unos cuantos años más hasta que el Partido Comunista, ya en el contexto de la Guerra Fría, decide abandonar la lucha armada. El nuevo contexto internacional definido por la Guerra Fría posibilitó a Franco ser un baluarte contra el comunismo y por esa razón en 1953 se firman los Acuerdos de Madrid por los que los americanos sitúan en el territorio varias bases militares. Cuando el Partido Comunista abandona la lucha armada es porque Stalin ha asumido que España está en la esfera de influencia de Estados Unidos. Los guerrilleros abandonados por todos son considerados por el régimen desde la promulgación de la Ley de represión del Bandidaje y el Terrorismo de abril de 1947, como simples bandidos, y por lo tanto erradicados sistemáticamente.

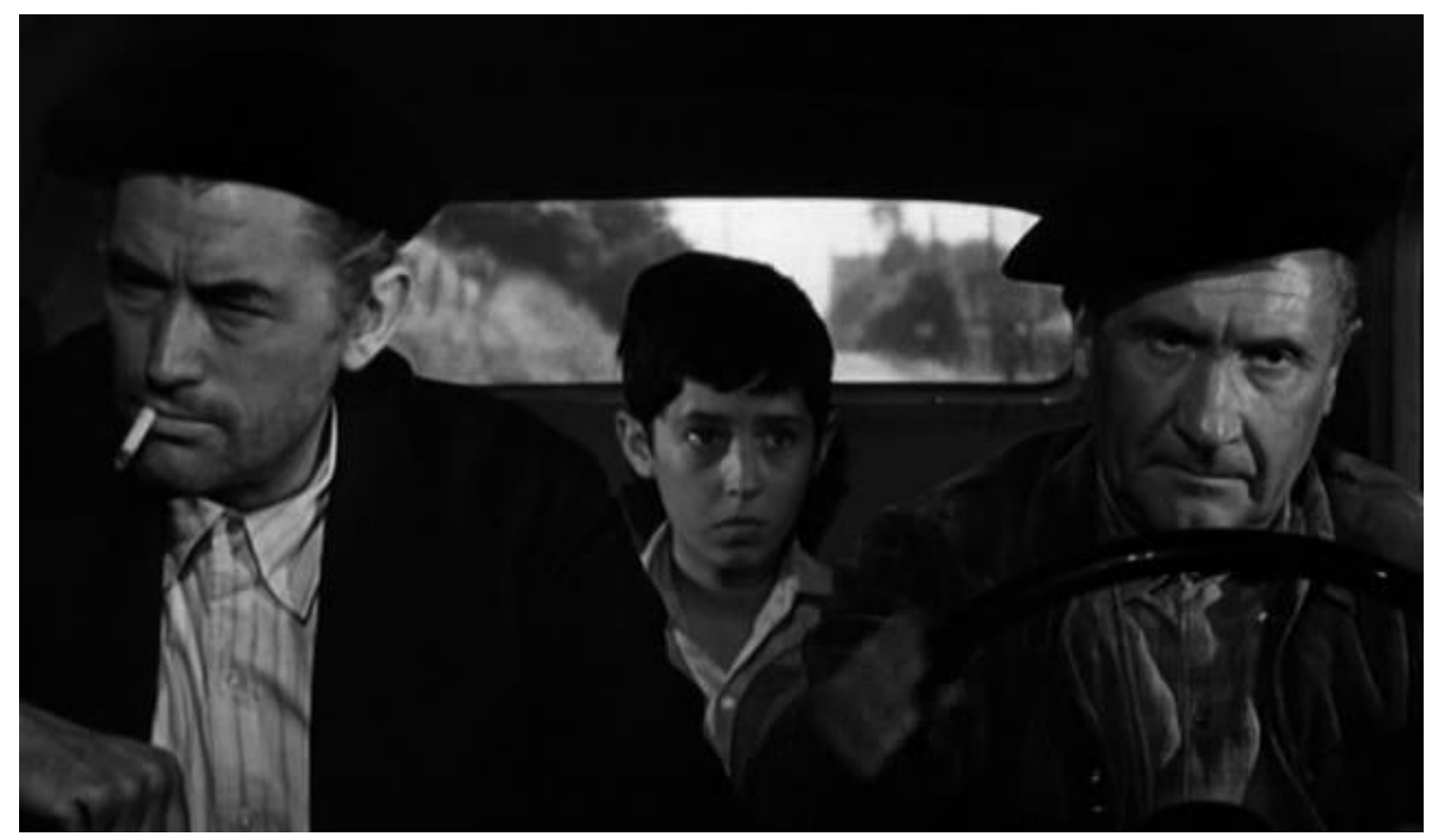

En 1964, los Estados Unidos se implican definitivamente en la guerra del Vietnam, probablemente el conflicto al que concurrieron más periodistas con una gran libertad para ejercer su oficio, y del que posteriormente surgieron multitud de películas. En España en el momento en que se estrena la película, el régimen estaba aplicando la política económica del Desarrollismo después de los duros años de la autarquía de la posguerra y ostracismo internacional. La década de los sesenta fue el momento de la apertura de España al mundo: fue el momento en que llegan miles de turistas, principalmente europeos, que al mismo tiempo que contribuyen con su paso a la economía del país, contagian a los españoles con sus ideas y forma de vidas. Sin embargo, pese a todo esto Y llego el día de la venganza pesaba demasiado, más cuando el régimen conmemoraba los 25 años de Paz en España, en los que se justificaba el alzamiento como algo inevitable, y en donde no había ninguna concesión ni equiparación hacía los perdedores de la guerra.

\footnotetext{
${ }^{7}$ Ibídem. Entre los represaliados no solo se encuentran los guerrilleros si no todos aquellos que les hacían de enlaces o les daban soporte de alguna u otra manera.
} 


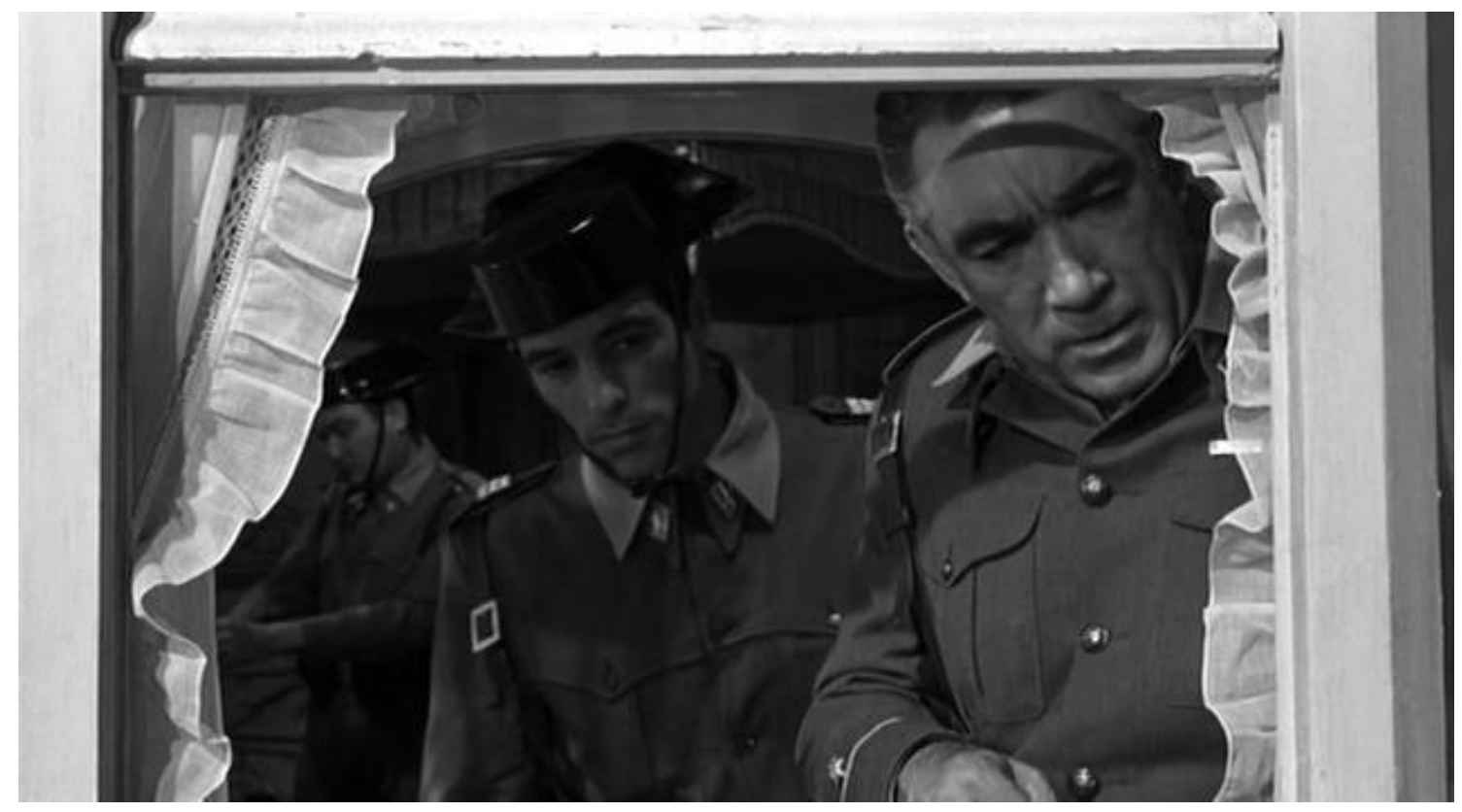

Pasamos a ver algunas claves del filme. Manuel Artigues está inspirado en Francisco Sabaté y el Capitán Viñolas lo está Eduardo Quíntela. Incluso el personaje de Carlos, confidente de la Guardia Civil que se dedica al contrabando, podría tener su correspondencia en Eliseo Melis Díaz y Antonio Seba Amores, confidentes que, según Antonio Téllez, habrían delatado a decenas de resistentes libertarios. La película fue rodada en el Pirineo francés en la que aparece la localidad de Pau, el santuario de Lourdes, y en el lado español, la ciudad imaginaria de San Martin. Entre los motivos de la prohibición de la película en España y las sanciones a la Columbia Pictures, como comentábamos más arriba, estaban las relaciones de Viñolas con su amiga o amante, y también con la joven prostituta del piso que ocupa la Guardia Civil. El régimen mantenía que dejaba en mal lugar a la Guardia Civil. Daba una mala imagen de España. Pero toda ella pesaba demasiado, y como leímos más arriba, este mismo régimen hizo todo lo posible para evitar no solo su proyección en España, si no su propia producción, y emisión en los Estados Unidos.

El Quico Sabaté fue un legendario guerrillero anarquista antifranquista que finalizada la Segunda Guerra Mundial, tal cómo nos relatan Antonio Téllez y Eric Hobsbawm ${ }^{8}$, lleva a cabo toda una serie de incursiones a través de los Pirineos, principalmente en la ciudad de Barcelona, en forma de atracos para obtener liquidez para la organización tanto en España como para el exilio en Toulouse, llamando a esto "expropiaciones", y atentados con el objetivo de eliminar a figuras representativas, odiosas para estos, como la de Eduardo Quíntela, el Comisario de la Brigada Político Social. Tanto uno como otro jugaran durante años al juego del ratón y el gato. El Movimiento libertario deja de apoyar también la lucha armada tanto por el cambio de contexto internacional como por la implacable represión en España de sus militantes, y la posibilidad de ilegalización de las organizaciones en territorio francés. Por lo que podemos decir que los guerrilleros anarquistas terminan quedándose solos hasta que llega el momento de su muerte. Sabaté en Francia es acusado de un atraco en una fábrica de Lyon donde se produjo un tiroteo con varias víctimas, por lo que durante un tiempo cesa en sus actividades, pero en 1960 vuelve a España por alguna razón -la Guardia Civil dijo que para vengar la muerte de sus dos hermanos- con un pequeño

8 TÉLlEZ, Antonio (2005) Sabaté. Guerrilla urbana en España (1945-1960). Virus Editorial. Barcelona. HOBSBAWM, Eric (2003) Bandidos. Crítica. Libros de Historia. Barcelona. 
grupo a España a través de los Pirineos: la Guardia Civil los localiza rápidamente y les cerca en una masía de la Garrotxa. Sabaté es herido en una pierna, pero logra huir en plena noche, sorteando a todos los guardias. Toma un tren en Massanet con dirección a Barcelona, pero este se detiene en Sant Celoni para cambiar de máquina. Sabaté se baja del tren y busca un médico, pero finalmente encuentra la muerte a manos de un Somatén y la Guardia Civil ${ }^{9}$.

Queda una pregunta inquietante en el aire: ¿Por qué volvió?

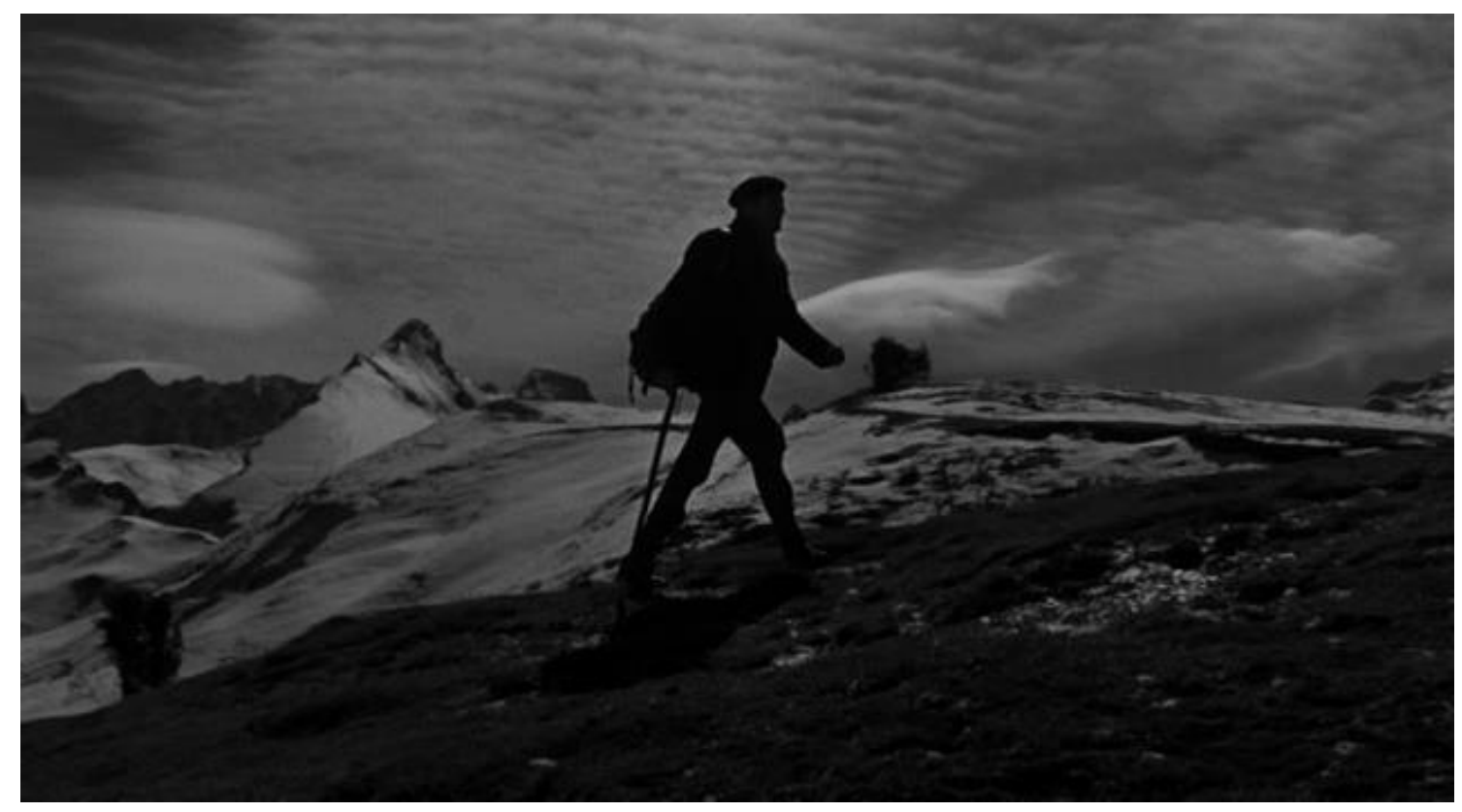

\section{Bibliografía consultada}

\section{Artículos}

-NOGALES CÁRDENAS, Pedro. PÉREZ-PORTABELLA LÓPEZ, Antonio. SUÁREZ FERNÁNDEZ, José Carlos (2015). Y llegó el día de la venganza. Franco contra Hollywood. V Congreso Internacional de Historia y Cine Histórico. Madrid. (https://e-

archivo.uc3m.es/bitstream/handle/10016/24915/Llego_Nogales_CIHC_2017.pdf).

SÁNCHEZ LOBERA, Francesc (2011) La guerrilla antifranquista. El Inconformista Digital. (http://www.elinconformistadigital.com/2011/07/11/la-guerrillaantifranquista-por-francesc-sanchez/)

SÁNCHEZ LOBERA, Francesc (2016) Refugiados. El Inconformista Digital. (http://www.elinconformistadigital.com/2016/01/27/refugiados-por-francescsanchez/)

\footnotetext{
${ }^{9}$ Algunas escenas de la película Metralleta Stein de José Antonio de la Loma son un calco tanto del último atraco y huida de Sabaté de España como su último viaje de vuelta con el grupo de compañeros. Sin embargo, en el filme de estética setentera, en el que no hay ningún signo político o referencia a la lucha antifranquista, el protagonista y su grupo son solo unos atracadores.
} 
SÁNCHEZ LOBERA, Francesc (2017) Exilio español en el norte de África. El Inconformista Digital. (http://www.elinconformistadigital.com/2017/02/14/exilioespanol-en-el-norte-de-africa-por-francesc-sanchez/).

\section{Libros}

BEEVOR, Antony (2015) La guerra civil española. Crítica. Barcelona.

HERNÁNDEZ SÁNCHEZ, Fernando (2018) La frontera salvaje. Un frente sombrío del combate contra Franco. Pasado y presente. Barcelona.

HOBSBAWM, Eric (2003) Bandidos. Crítica. Libros de Historia. Barcelona.

MATEOS, Abdón. (2011) Historia del Antifranquismo. Historia, interpretación y uso del pasado. Flor del Viento Ediciones. Colección Con Franco vivíamos peor. Barcelona.

MESQUIDA, Evelyn (2018) La Nueve. Los españoles que liberaron París. Penguin Random House. Barcelona.

MUNIESA, Bernat. (2005) Dictadura y Transición. La España lampedusiana. I: La dictadura franquista. 1939-1975. Publicacions de la Universitat de Barcelona. Barcelona.

SERRANO, Secundino. (2001) Maquis. Historia de la guerrilla antifranquista. Temas de hoy. Historia. Madrid.

TÉLLEZ, Antonio (2005) Sabaté. Guerrilla urbana en España (1945-1960). Virus Editorial. Barcelona.

TÉLLEZ, Antonio (2004) Facerías. Guerrilla urbana (1939-1957). Virus Editorial. Barcelona.

FRANCESC SÁNCHEZ LOBERA es investigador del Centre d'Investigacions Film Història de la Universitat de Barcelona, doctorando en el programa Societat $i$ Cultura de la Universitat de Barcelona, master en Estudis Històrics en la mención de Historia Contemporánea, y licenciado en Historia (especialidad en Historia Contemporánea), ambos estudios por la Universitat de Barcelona. Es también director de la publicación El Inconformista Digital (www.elinconformistadigital.com).

$$
\text { email- } \underline{\text { francescsanchezcine@ gmail.com }}
$$

